\title{
Impact of COVID-19 online classes on morningness-eveningness personality among adult college students: A survey study
}

\author{
Vignesh Srinivasan*, Surya Vishnuram, Prathap Suganthirababu, A. Kumaresan, P. Divyalaxmi, \\ M. Saranya Devi and Jagatheesan Alagesan \\ Saveetha College of Physiotherapy, SIMATS, Chennai, India
}

Received 8 April 2021

Accepted 15 July 2021

\begin{abstract}
.
BACKGROUND: COVID-19 emerged as a serious pandemic in 2019 and billions of people were infected. Various precautionary methods were taken to contain the spread of virus such as social distancing, public lockdown, sanitation, and closure of schools and colleges. Many colleges started online classes to resume their syllabus and to complete the course curriculum. These evening online sessions resulted in late night sleep, long term mobile/computer exposure, and disturbed sleep pattern. OBJECTIVE: The present study aimed to determine the impact of COVID-19 online classes on morningness- eveningness personality and to compare it with different age groups, gender, and body mass index.

METHODS: The cluster sampling method was used to collect the subjects from the total of 1153 adult college students, 897 subjects were selected based on the selection criteria and instructed to submit an online survey consists of the Morningnesseveningness Questionnaire and demographic and anthropometric data through mail, social media, or through a researcher by direct interview.

RESULTS: The mean score for the 897 participants is 56.7, indicating intermediate morningness-eveningness personality type. On comparing the different groups, the youngest group $(18-20$ years) scored $4.23 \%$ (mean $=46.7)$, female subjects scored $6.13 \%($ mean $=58.1)$, the underweight $2.67 \%($ mean $=59.2)$ and overweight groups scored $2.89 \%($ mean $=59.7)$ indicating definite eveningness. Among the 897 collected samples of the population $8.13 \%$ of the subjects experienced definite eveningness, $14.93 \%$ has moderate eveningness, $17.38 \%$ are under intermediate category, $22.4 \%$ have moderate morningness, and $37.11 \%$ have definite morningness.
\end{abstract}

CONCLUSIONS: Subjects with eveningness personality have high risk of developing mental illness, thus it's important to determine the eveningness personality among student population to avoid serious complications in later age.

Keywords: Pandemic, sleep-wake transition disorders, circardian rhythm, student health services, mental health

*Address for correspondence: Vignesh Srinivasan, Tutor, Saveetha College of Physiotherapy, SIMATS, Chennai, India. E-mail: vigneshphysio1989@gmail.com. 


\section{Introduction}

COVID-19 emerged as a serious pandemic in 2019 and billions of people were infected. Various precautionary methods were taken to contain the spread of virus such as social distancing, public lockdown, sanitation, and closure of schools and colleges [13]. These measures include work from home [4] and lockdown resulted in major economic crisis and affected many fields including educational institutions. Many colleges started online classes to resume their syllabus and to complete the course curriculum, as the online classes were flexible and easier with no geographical need; most of the students and faculties preferred it [5].

Online classes can be schedulable at any time and the majority of the classes, webinars, conferences, and online meetings were conducted at evening time. These evening online sessions resulted in late night sleep, long term mobile/computer exposure, and disturbed sleep pattern [6]. Due to this reason, diurnal preferences of the students changed and many students altered their active lifestyle to evening [7]. Earlier studies reported that altered sleep-wake cycle disturbs a person psychologically, physically, and socially [8-11].

Morningness-eveningness means the diurnal preferences of an individual, sleep-wake cycle, and active lifestyle in morning or evening. Early larks are the persons who were more active in morning, sleep early, and perform their best at morning hours. Night owls are the persons who were more active in evening, sleep at late-night, and wake lately in the morning, and perform their best at evening hours [12, 13]. These different sleep preferences have significant effect on physical, psychological, and mental health. Diurnal preferences have serious impact on various behaviors such as, food intake, sleeping, alcohol use, smoking, and drug abuse $[14,15]$. Several studies reported that eveningness is strongly related with non-habitual behaviors and health-impairing habits, whereas morningness is strongly related to health-improving habits [16, 17]. The Morningnesseveningness Questionnaire is a valid and reliable tool used to identify the morningness and eveningness type personality and it contains 19-items (getting up in the morning, sleeping time, most active time, etc.). Previous researches studied the relationship between morningness-eveningness and age, gender, body mass index (BMI), smoking, alcohol abuse, and various habits [18-20]. The present study aimed to determine the impact of COVID-19 online classes on morningness-eveningness personality and to compare it with different age groups, gender, and BMI.

\section{Methods}

\subsection{Participants and procedure}

The study was approved by the Institution Review Board of the University (04/01/2021/ISRB/FR/ SCPT) and was approved by the Ethics Committee prior to the start of the study. Participants were invited through notice boards, social media messages, and personal contact from their college registry. The cluster sampling method was used to collect the subjects from the total of 1153 adult college students from SIMATS University, Chennai, India who were willing to take part in the study. Among the 1153 students, 897 subjects were selected based on the selection criteria. The selected subjects were explained in detail about the study processes and instructed to submit an online survey consisting of the Morningness-eveningness questionnaire and demographic and anthropometric data through mail, social media, or through a researcher by direct interview.

\subsection{Selection criteria}

The adult college students of both genders under the age of 26 years with regular attendance more than $85 \%$ in online classes, subjects with normal physical and mental health status were included for the study. Subjects with previous mental, physical, or psychological illness; subjects under medications or treatment for any illness; subjects with chronic medical conditions involving cardiac, pulmonary, orthopedic, neurological, or psychosomatic systems were excluded from the study.

\subsection{Outcome measures}

\subsubsection{The Morningness-eveningness Questionnaire}

The 19-item questionnaire interprets the diurnal preferences using the number of points for each question, the total score ranges from 16-86 indicating $16-30$ as definite evening; $31-41$ as moderate evening; $42-58$ as intermediate; $59-69$ as moderate morning; and 70-86 as definite morning [21, 22].

\subsubsection{Demographic data}

Demographic data such as age, gender, academic profile, medical history, surgical history, personal 
Table 1

Demographic and anthropometric data of the subjects

\begin{tabular}{|c|c|c|c|c|c|c|c|c|c|}
\hline & \multicolumn{3}{|c|}{ Age group } & \multicolumn{2}{|c|}{ Gender } & \multicolumn{4}{|c|}{ Body mass index } \\
\hline & $18-20$ & $21-23$ & $24-26$ & M & $\mathrm{F}$ & $<18$ & $19-24$ & $25-29$ & $30>$ \\
\hline No. of participants & 529 & 357 & 11 & 389 & 508 & 251 & 391 & 243 & 12 \\
\hline Percentage & $58.9 \%$ & $39.7 \%$ & $1.2 \%$ & $43 \%$ & $57 \%$ & $27.9 \%$ & $43.6 \%$ & $27.1 \%$ & $1.3 \%$ \\
\hline
\end{tabular}

Table 2

Mean morningness-eveningness score of the subjects and number of subjects in each category

\begin{tabular}{|c|c|c|c|c|c|c|c|c|c|c|}
\hline & \multicolumn{3}{|c|}{ Age group } & \multicolumn{2}{|c|}{ Gender } & \multicolumn{4}{|c|}{ Body mass index } & \multirow[t]{2}{*}{ Total } \\
\hline & $18-20$ & $21-23$ & $24-26$ & M & $\mathrm{F}$ & $<18$ & $19-24$ & $25-29$ & $30>$ & \\
\hline Definite morning & 218 & 112 & 3 & 154 & 179 & 88 & 147 & 96 & 2 & 333 \\
\hline Moderate morning & 122 & 77 & 2 & 98 & 103 & 57 & 86 & 57 & 1 & 201 \\
\hline Intermediate & 83 & 71 & 2 & 64 & 92 & 51 & 76 & 28 & 1 & 156 \\
\hline Moderate evening & 68 & 65 & 1 & 55 & 79 & 31 & 64 & 36 & 3 & 134 \\
\hline Definite evening & 38 & 32 & 3 & 18 & 55 & 24 & 18 & 26 & 5 & 73 \\
\hline Mean score & 46.7 & 67.5 & 52.1 & 61.8 & 58.1 & 59.2 & 60.6 & 59.7 & 41.3 & 56.7 \\
\hline
\end{tabular}

Table 3

Percentage of number of subjects in each MEQ category

\begin{tabular}{|c|c|c|c|c|c|c|c|c|c|c|}
\hline & \multicolumn{3}{|c|}{ Age group } & \multicolumn{2}{|c|}{ Gender } & \multicolumn{4}{|c|}{ BMI } & \multirow[t]{2}{*}{ Total } \\
\hline & $18-20$ & $21-23$ & $24-26$ & M & $\mathrm{F}$ & $<18$ & $19-24$ & $25-29$ & $30>$ & \\
\hline Definite morning & $24.3 \%$ & $12.48 \%$ & $0.33 \%$ & $17.16 \%$ & $19.95 \%$ & $9.8 \%$ & $16.38 \%$ & $10.7 \%$ & $0.22 \%$ & $37.11 \%$ \\
\hline Moderate morning & 13.60 & $8.58 \%$ & $0.22 \%$ & $10.92 \%$ & $11.48 \%$ & $6.35 \%$ & $9.58 \%$ & $6.35 \%$ & $0.11 \%$ & $22.4 \%$ \\
\hline Intermediate & $9.25 \%$ & $7.91 \%$ & $0.22 \%$ & $7.13 \%$ & $10.25 \%$ & $5.68 \%$ & $8.4 \%$ & $3.12 \%$ & $0.11 \%$ & $17.38 \%$ \\
\hline Moderate evening & $7.58 \%$ & $7.24 \%$ & $0.11 \%$ & $6.13 \%$ & $8.80 \%$ & $3.45 \%$ & $7.13 \%$ & $4.01 \%$ & $0.33 \%$ & $14.93 \%$ \\
\hline Definite evening & $4.23 \%$ & $3.56 \%$ & $0.33 \%$ & $2 \%$ & $6.13 \%$ & $2.67 \%$ & $2 \%$ & $2.89 \%$ & $0.55 \%$ & $8.13 \%$ \\
\hline
\end{tabular}

history including smoking, alcohol, drugs intake was collected.

The subjects were grouped based on their gender (male, female) and age (18-20 years, 21-23 years, and 24-26 years).

\subsubsection{Anthropometric data}

The height in meters and weight in kilograms of each subjects were also collected subjectively and the BMI was calculated using the formula $\mathrm{kg} / \mathrm{m}^{2}$ and it represents the body fat. BMI less than 18.5 indicates underweight, 18.5-24.9 indicates normal weight, 25-29.9 indicates overweight, and above 30 indicates obesity. BMI values are highly reliable and valid measures in assessing the body fat $[23,24]$.

\section{Data analysis}

Descriptive statistics using percentages and mean were used to analyze the desired objectives from the selected subjects. Initially the demographic and anthropometric data of participants (age, gender and $\mathrm{BMI}$ ) are studied and the percentage of each group is calculated based on number of subjects in each group.
Table 1 represents the demographic and anthropometric data of the subjects along with percentage.

A total score per participant from the Morningnesseveningness Questionnaire is calculated and the personality is categorized into 5 major types based on number of participants. The mean of all participants score for each group is also calculated and compared with different age groups (18-20 years, 21-23 years, 24-26 years), different BMI groups (underweight, normal, overweight, obese), and different gender. Table 2 represents the number of participants under each personality type and the mean morningnesseveningness scores of each group. The percentage of subjects in each personality types is calculated and compared with each other as shown in Table 3. The chi square analysis was performed for different age groups, BMI groups and gender to determine the influence on eveningness.

\section{Results}

\subsection{Sample characteristics}

Among the 1153 university students, 676 were excluded based on selection criteria and 897 took part 


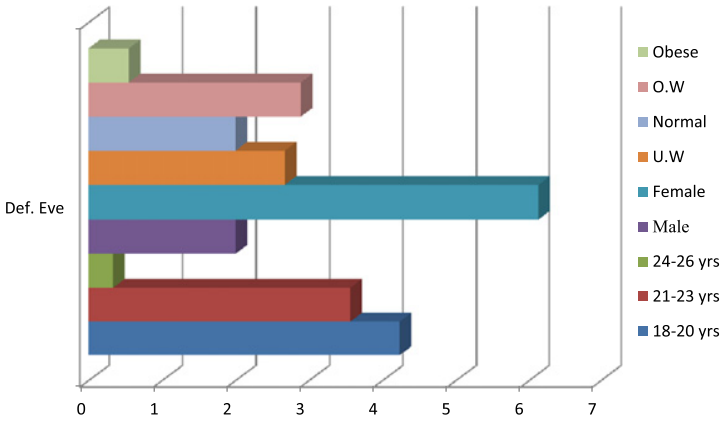

Fig. 1. Graphical representation of mean values of definite eveningness.

in this study. The average age is 20.26 years, with more female students $(508,57 \%)$ compared to male students $(389,43 \%)$. Around $58.9 \%$ of participants are aged 18 to 20 years, $39.7 \%$ of participants are aged 21 to 23 years, $1.2 \%$ of participants aged $24-26$ years. In terms of BMI, $27.9 \%$ subjects are underweight; $43.6 \%$ subjects are normal; $27.1 \%$ subjects are overweight; $1.3 \%$ subjects are obese. The overall percentage calculation is shown in Table 1 . The mean score for the 897 participants is 56.7 , indicating intermediate morningness-eveningness personality type. However, the mean values of each group must be studied separately to understand the differences between groups and within each group.

\subsection{Morningness-eveningness with age groups}

On comparing the different age groups, the youngest group (18-20 years) shows high definite eveningness $4.23 \%$ (mean $=46.7$ ) while comparing with other two groups $3.56 \%$ and $0.33 \%$ (mean= $67.5,52.1)(21-23$ years and $24-26$ years). It is also noted that $7.58 \%$ of the youngest group experience moderate eveningness, which is higher than other two groups $(7.24 \%$ and $0.11 \%)$.

\subsection{Morningness-eveningness with gender}

While comparing the gender, female subjects show high definite eveningness $6.13 \%($ mean $=58.1)$ on comparing with male subjects $2 \%($ mean $=61.8)$. Also $8.8 \%$ of the female subjects experience moderate eveningness, which is higher than the male subjects $6.13 \%$.

\subsection{Morningness-eveningness with BMI}

On comparing the different BMI groups, the underweight $2.67 \%$ (mean $=59.2$ ) and overweight groups $2.89 \%$ (mean $=59.7$ ) has higher definite eveningness than normal and obese subjects $2 \%($ mean $=60.6)$ and $0.55 \%$ (mean $=41.3)$ respectively. It is noted that the obese subjects has the lowest mean score (41.3), while comparing with other groups. Also $7.13 \%$ of normal BMI subjects experience moderate eveningness, which is higher than other three groups $(3.45 \%$, $4.01 \%$, and $0.33 \%$ ).

\subsection{Chi square analysis}

The chi square analysis of age influence on eveningness was carried out categorizing the age groups into three (18-20, 21-23, and 24-36). The chi-square statistic is 18.4959 and the $p$-value is 0.017801 . The result is significant at $p<0.05$, indicating association between eveningness and age. Higher the age, the risk of eveningness increases.

The chi square analysis of BMI influence on eveningness was carried out categorizing the age groups into three (18-20,21-23, and 24-36). The chisquare statistic is 38.45 and the $p$-value is 0.00013 . The result is significant at $p<0.05$, indicating association between eveningness and BMI. Higher the BMI, the risk of eveningness increases.

The chi square analysis of gender influence on eveningness was carried out categorizing the age groups into three (18-20, 21-23, and 24-36). The chi-square statistic is 14.54 and the $p$-value is 0.057 . The result is significant at $p<0.05$, indicating association between eveningness and gender and women show higher eveningness.

\section{Discussion}

College students are most vulnerable population who are at high risk to mental health issues $[25,26]$. The findings of this study enlighten the impact of COVID-19 online classes on the morningness-eveningness type personality of this specific population. Our findings indicate, about $8.13 \%$ of the adult college students experience definite eveningness and $14.93 \%$ have moderate eveningness during the COVID-19 pandemic. The negative impacts associated with eveningness were previously studied [27-29] and considered to seek management as soon as possible. 
An online survey with the Morningness-eveningness Questionnaire along with demographic and anthropometric data during this pandemic helped us to determine the negative side of online classes and to prevent such mental illness to the vulnerable population.

Mental illnesses such as stress, anxiety, depression, and sleep disturbance due to eveningness have been studied earlier [29-31], but the impact of COVID19 on morningness-eveningness has not yet been studied.

This study shows that female subjects show high definite eveningness than male subjects, this might be due to household work as well as the combination of studies and work might affect the sleep-wake cycle and also unequal group distribution may result in statistical deviations.

Among the age groups, the youngest population has lesser score and high rate in definite eveningness. The younger population tends to sleep more and the exposure of bright light from mobile phones or computer screens might induce prolonged sleep and waking up late. Unequal group size may influence the results.

While comparing the BMI differences, the underweight subjects and the overweight subjects have higher eveningness rate, as reported in previous studies easier fatigue might cause increased sleeping hours, unequal group size on this category might also influenced the results. A previous study by Achari et al. revealed that intermediate type has the highest prevalence among Indian students with eveningness of $1.93 \%$ and morningness of $35.34 \%$ [32]. However, the present study showed that $8.13 \%$ of the subjects had an eveningness personality indicating the increase in eveningness personality might be an effect of online classes. Hence, the subjects with eveningness have a high risk of developing mental illness and psychoactive substance intake [33, 34], and can avail benefits from the available treatment approaches [35].

This study is not without limitations. This is a single center study with an unequal sample size. Subjective data for BMI might be from the assumption of the subjects. Descriptive statistics was used to analyze the data. This is as a major limitation factor to define a proper conclusion. Furthermore, more studies focusing on age, gender and BMI with equal sample sizes and a relationship study to correlate morningness-eveningness with the categories and inferential statistics can be done in the future for more detailed knowledge on morningnesseveningness personality.

\section{Conclusion}

Among the 897 collected samples of the population $8.13 \%$ of the subjects experienced definite eveningness, $14.93 \%$ had moderate eveningness, $17.38 \%$ are under intermediate category, $22.4 \%$ had moderate morningness, and $37.11 \%$ had definite morningness. Further data analysis showed females were more common to eveningness than male, subjects ageing between 18-20 years and subjects under underweight and overweight category have high rate in definite eveningness. As the statistical data were analyzed only descriptively, it is essential to study the sample population with inferential statistics to draw a definite conclusion. It also concluded that subjects with eveningness personality have high risk of developing mental illness, thus it's important to determine the eveningness personality among the student population to avoid serious complications in later age.

\section{Acknowledgments}

The authors acknowledge the immense help received from the scholars whose articles are cited and included in references of this manuscript. The authors are also grateful to authors/editors/publishers of all those articles, journals and books from where the literature for this article has been reviewed and discussed.

\section{Conflict of interest}

The authors report no conflict of interest.

\section{References}

[1] Acter T, Uddin N, Das J, Akhter A, Choudhury TR, Kim S. Evolution of severe acute respiratory syndrome coronavirus 2 (SARS-CoV-2) as coronavirus disease 2019 (COVID-19) pandemic: A global health emergency. Science of the Total Environment. 2020 Apr 30:138996.

[2] Mustafa N. Impact of the 2019-20 coronavirus pandemic on education. International Journal of Health Preferences Research. 2020:1-2.

[3] Dubey S, Biswas P, Ghosh R, Chatterjee S, Dubey MJ, Chatterjee S, Lahiri D, Lavie CJ. Psychosocial impact of COVID-19. Diabetes \& Metabolic Syndrome: Clinical Research \& Reviews. 2020;14(5):779-88.

[4] Lopez-Leon S, Forero DA, Ruiz-Díaz P. Recommendations for working from home during the pandemic (and Beyond). Work. 2020 Jan 1(Preprint):1-5 
[5] Abbasi MS, Ahmed N, Sajjad B, Alshahrani A, Saeed S, Sarfaraz S, Alhamdan RS, Vohra F, Abduljabbar T. E-Learning perception and satisfaction among health sciences students amid the COVID-19 pandemic. Work. 2020; 67(3):549-556.

[6] Touitou Y, Touitou D, Reinberg A. Disruption of adolescents' circadian clock: The vicious circle of media use, exposure to light at night, sleep loss and risk behaviors. Journal of Physiology-Paris. 2016;110(4):467-79.

[7] Medeiros AL, Mendes DB, Lima PF, Araujo JF. The relationships between sleep-wake cycle and academic performance in medical students. Biological rhythm research. 2001;32(2):263-70.

[8] Kirby M, Maggi S, D'Angiulli A. School start times and the sleep-wake cycle of adolescents: a review and critical evaluation of available evidence. Educational Researcher. 2011;40(2):56-61.

[9] Majumdar P, Biswas A, Sahu S. COVID-19 pandemic and lockdown: cause of sleep disruption, depression, somatic pain, and increased screen exposure of office workers and students of India. Chronobiology International. 2020;37(8): 1191-200.

[10] Memari A, Shariat A, Anastasio A, Hakakzadeh A. Rising incidence of musculoskeletal discomfort in the wake of the COVID-19 crisis. Work. 2020 Jan 1(Preprint):1-3.

[11] Nambiar D. The impact of online learning during COVID19: students' and teachers' perspective. The International Journal of Indian Psychology. 2020;8(2):783-93.

[12] Hasler BP, Allen JJ, Sbarra DA, Bootzin RR, Bernert RA. Morningness-eveningness and depression: Preliminary evidence for the role of the behavioral activation system and positive affect. Psychiatry research. 2010;176(2-3):166-73.

[13] Kudielka BM, Federenko IS, Hellhammer DH, Wüst S. Morningness and eveningness: the free cortisol rise after awakening in "early birds" and "night owls". Biological psychology. 2006;72(2):141-6.

[14] Togo F, Yoshizaki T, Komatsu T. Association between depressive symptoms and morningness-eveningness, sleep duration and rotating shift work in Japanese nurses. Chronobiology international. 2017;34(3):349-59.

[15] Nakade M, Takeuchi H, Kurotani M, Harada T. Effects of meal habits and alcohol/cigarette consumption on morningness-eveningness preference and sleep habits by Japanese female students aged 18-29. Journal of physiological anthropology. 2009;28(2):83-90.

[16] Kanerva N, Kronholm E, Partonen T, Ovaskainen ML, Kaartinen NE, Konttinen H, Broms U, Männistö S. Tendency toward eveningness is associated with unhealthy dietary habits. Chronobiology International. 2012;29(7): 920-7.

[17] Randler C. Association between morningness-eveningness and mental and physical health in adolescents. Psychology, Health \& Medicine. 2011;16(1):29-38.

[18] Cavallera GM, Giudici S. Morningness and eveningness personality: A survey in literature from 1995 up till 2006. Personality and Individual Differences. 2008;44(1):3-21.

[19] Adan A, Natale V. Gender differences in morningnesseveningness preference. Chronobiology International. 2002;19(4):709-20.
[20] Türkoğlu S, Çetin FH. The relationship between chronotype and obesity in children and adolescent with attention deficit hyperactivity disorder. Chronobiology International. 2019;36(8):1138-47.

[21] Terman M, Rifkin J, Jacobs J, White T, Home J, Ostberg O Morningness-eveningness questionnaire. Int J Chronobiol. 1976;4:97-100.

[22] Tonetti L. Validity of the Morningness-Eveningness Questionnaire foe adolescents (MEQ-A). Sleep and Hypnosis. 2007;9(2):47.

[23] Vainio H, Bianchini F, editors. Weight control and physical activity. Iarc; 2002.

[24] Deurenberg P, Weststrate JA, Seidell JC. Body mass index as a measure of body fatness: age-and sex-specific prediction formulas. British Journal of Nutrition. 1991;65(2):105-14.

[25] Balon R, Beresin EV, Coverdale JH, Louie AK, Roberts LW. College mental health: a vulnerable population in an environment with systemic deficiencies.

[26] Blanco C, Okuda M, Wright C, Hasin DS, Grant BF, Liu SM, Olfson M. Mental health of college students and their non-college-attending peers: Results from the national epidemiologic study on alcohol and related conditions. Archives of General Psychiatry. 2008;65(12):1429-37.

[27] Jankowski KS. The role of temperament in the relationship between morningness- eveningness and mood. Chronobiology International. 2014;31(1):114-22.

[28] Hairston IS, Shpitalni R. Procrastination is linked with insomnia symptoms: The moderating role of morningnesseveningness. Personality and Individual Differences. 2016; 101:50-6.

[29] Cox RC, Olatunji BO. Eveningness Predicts Negative Affect Following Sleep Restriction. Behavior Therapy. 2020 Oct 26.

[30] Prieto PD, Díaz-Morales JF, Barreno CE, Mateo MJ, Randler C. Morningness- eveningness and health-related quality of life among adolescents. The Spanish Journal of Psychology. 2012;15(2):613-23.

[31] Díaz-Morales JF. Anxiety during adolescence: considering morningness-eveningness as a risk factor. Sleep and Biological Rhythms. 2016;14(2):141-7.

[32] Achari KV, Pati AK. Morningness-eveningness preference in Indian school students as function of gender, age and habitat. Biological Rhythm Research. 2007;38(1):1-8.

[33] Altena E, Baglioni C, Espie CA, Ellis J, Gavriloff D, Holzinger B, Schlarb A, Frase L, Jernelöv S, Riemann D. Dealing with sleep problems during home confinement due to the COVID-19 outbreak: Practical recommendations from a task force of the European CBT-I Academy. Journal of Sleep Research. 2020;29(4):e13052.

[34] Urbán R, Magyaródi T, Rigó A. Morningness-eveningness, chronotypes and health-impairing behaviors in adolescents. Chronobiology International. 2011;28(3):238-47.

[35] Eastman CI, Boulos Z, Terman M, Campbell SS, Dijk DJ, Lewy AJ. Light treatment for sleep disorders: consensus report: VI. Shift work. Journal of Biological Rhythms. 1995;10(2):157-64. 